\title{
Neurosurgery in the Treatment of Alcohol Use Disorder: A Systematic Literature Review
}

\section{Neurocirurgia no tratamento do transtorno por uso de álcool: Uma revisão sistemática da literatura}

\author{
Bruna Veronese de Almeida1이 Ledismar José da Silva ${ }^{20}$ \\ ${ }^{1}$ School of Medicine, Pontifícia Universidade Católica de Goiás, \\ Goiânia, Goiás, Brazil \\ ${ }^{2}$ Department of Neurosurgry, School of Medicine, Pontifícia \\ Universidade Católica de Goiás, Goiânia, Goiás, Brazil
}

\begin{abstract}
Address for correspondence Ledismar José da Silva, MD, MSc, Departamento de Medicina, Pontifícia Universidade Católica de Goiás (PUC-Goiás), Avenida Universitária, 1440, Setor Universitário, 74605010, Goiânia, Goiás, Brasil (e-mail: ledismarsilva@gmail.com).
\end{abstract}

Arq Bras Neurocir 2022;41(1):e76-e84.

\begin{abstract}
Keywords

- alcoholism

- ablation techniques

- deep brain stimulation

- neurosurgery
\end{abstract}

Resumo
Alcohol abuse has impacts on public health worldwide. Conservative treatment to achieve abstinence consists of detoxification combined with psychotherapy and the use of drugs, but it is estimated that only half of the individuals achieve long-term abstinence with the available treatments. In this sense, neurosurgery appears as a therapeutic proposal. The present study aimed to gather information about the circuitry related to alcohol use disorder (AUD), to describe possible surgical targets, and to establish whether a surgical approach could be a safe and effective treatment option. A systematic review of the literature was conducted and reported according to the Preferred Reporting Items for Systematic Reviews and Meta-analyses (PRISMA) statement. The 14 selected articles analyze ablative operations, deep brain stimulation (DBS), and a new procedure in which the patient is first submitted to repetitive transcranial magnetic stimulation to evaluate their response, and later an implant is surgically positioned on the evaluated target to obtain more lasting results. The most relevant outcomes were found when the anterior cingulate cortex (ACC) and the nucleus accumbens (NAcc) were used as targets, demonstrating a large reduction in alcohol intake and even its cessation. However, important side effects were observed, such as psychotic symptoms, right frontal venous infarction, seizures after implantation in the ACC and a hypomanic period after DBS in the NAcc, which could be reversed. Due to the lack of studies involving the surgical treatment of AUD, more clinical trials are needed to compare targets, to assess surgical techniques, and to estimate the safety of these techniques.

O abuso de álcool tem impacto na saúde pública em todo o mundo. O tratamento conservador para alcançar a abstinência consiste na desintoxicação combinada com psicoterapia e uso de drogas, mas estima-se que apenas metade dos indivíduos alcance received

October 21, 2020

accepted

March 9, 2021

published online

February 16, 2022
DOI https://doi.org/ $10.1055 / \mathrm{s}-0041-1733866$. ISSN 0103-5355.

\footnotetext{
(c) 2022. Sociedade Brasileira de Neurocirurgia. All rights reserved. This is an open access article published by Thieme under the terms of the Creative Commons Attribution-NonDerivative-NonCommercial-License, permitting copying and reproduction so long as the original work is given appropriate credit. Contents may not be used for commercial purposes, or adapted, remixed, transformed or built upon. (https://creativecommons.org/ licenses/by-nc-nd/4.0/) Thieme Revinter Publicações Ltda., Rua do Matoso 170, Rio de Janeiro, RJ, CEP 20270-135, Brazil
} 


\author{
Palavras-chave \\ - alcoolismo \\ - técnicas de ablação \\ - estimulação cerebral \\ profunda \\ - neurocirurgia
}

a abstinência de longo prazo com os tratamentos disponíveis. Nesse sentido, a neurocirurgia surge como proposta terapêutica. O presente estudo teve como objetivo reunir informações sobre a neurocircuitaria relacionada ao transtorno por uso de álcool, descrever possíveis alvos cirúrgicos e estabelecer se a abordagem cirúrgica pode ser uma opção de tratamento segura e eficaz. Foi realizada uma revisão sistemática da literatura de acordo com a declaração Principais Itens para Relatar Revisões sistemáticas e Metanálises (PRISMA, na sigla em inglês). Os 14 artigos selecionados analisam técnicas ablativas, estimulação cerebral profunda (ECP) e um novo procedimento no qual o paciente é primeiramente submetido à estimulação magnética transcraniana repetitiva para avaliar sua resposta e, posteriormente, um implante é posicionado cirurgicamente no alvo avaliado para obter resultados mais duradouros. Os desfechos mais relevantes foram encontrados quando o córtex cingulado anterior (CCA) e o núcleo accumbens (NAcc) foram usados como alvos, demonstrando uma grande redução na ingestão de álcool e até mesmo sua cessação. No entanto, foram observados efeitos colaterais importantes, como sintomas psicóticos, infarto venoso frontal direito e convulsões após implantação no CCA e período hipomaníaco após ECP no NAcc, que podem ser revertidos. Devido à falta de estudos envolvendo o tratamento cirúrgico do transtorno por uso de álcool, mais ensaios clínicos são necessários para comparar alvos, avaliar técnicas cirúrgicas e estimar a segurança dessas técnicas.

\section{Introduction}

Alcohol is an ancient substance rooted in social practices and related to cultural, religious, and economic issues. Its abusive consumption has an important impact on public health worldwide. It is estimated that, in 2016, it led to 3 million deaths, corresponding to $5.3 \%$ of the total deaths in the world and exceeding those caused by tuberculosis, HIV, diabetes, hypertension, and violence. ${ }^{1}$ In addition, it is an important morbidity factor that is associated with mental and behavioral disorders, cardiovascular and liver diseases, and with an increased incidence of suicide and injuries to third parties. ${ }^{2}$

Alcohol use disorder (AUD) is characterized by a pattern of problematic use, leading to clinically significant impairment or suffering. It includes withdrawal symptoms, tolerance, and craving, in addition to an abandonment or a decrease in professional, social, or recreational activities. ${ }^{3}$

Conservative treatment to achieve abstinence consists of detoxification combined with psychotherapy and the use of drugs. The drugs used are benzodiazepines as coadjuvants in detoxification and alcohol withdrawal, constituting the acute phase of treatment. Disulfiram, naltrexone, and acamprosate are used to prevent relapse, making up the chronic phase. $^{4}$

It is estimated that only half of the individuals achieve long-term abstinence with the available treatments. ${ }^{4,5} \mathrm{Neu}-$ rosurgery using ablative techniques or deep brain stimulation (DBS) appears in this sense as a therapeutic proposal. Deep brain stimulation uses electrodes implanted in certain targets established millimetrically by stereotaxy, seeking to modulate neuronal electrical activity. ${ }^{6}$

Given the global epidemiological magnitude of alcoholism, the high rate of recurrence after conservative treatment, and its economic impact on society, there is a demand for more studies on surgical treatments for these patients that describe the surgical targets and address criteria for surgical indications. Thus, the aim of the present study was to establish whether surgical treatment is a valid and effective therapeutic option in the treatment of alcoholism.

\section{Methods}

\section{Literature Search}

The present study was conducted and reported according to the Preferred Reporting Item for Systematic Reviews and Meta-Analysis (PRISMA) statement.

An electronic search was conducted in the Biblioteca Virtual en Salud (BVSalud), PubMed, and Cochrane Library databases in June 2020. The search was performed using medical subject headings (MeSH) combined with Boolean operators. The following search terms were used: alcoholism AND neurosurgery, alcoholism AND deep brain stimulation, and alcoholism AND Stereotaxic Techniques.

The following filters were used: available in full text, studies written in English, Spanish, or Portuguese; studies in humans; of all ages; and both genders. All articles published before May 2020 were retrieved.

\section{Study Selection}

The inclusion criteria were the following: available in full text, randomized clinical trials, and case reports about neurosurgery in patients with AUD. Studies were excluded if they involved noninvasive procedures or were animalrelated; if they did not apply to the key question; if they did not address a relevant outcome; if they did not have a clear description of the methods; or if they were review articles, 
abstracts, editorials, comments, or studies unrelated to surgical procedures performed in humans.

Duplicated studies were excluded using Zotero (version 5.0.66, Andrew W. Mellon Foundation, Institute of Museum and Library Services, Alfred P. Sloan Foundation, VA, USA). Titles and abstracts were reviewed independently by two authors (Almeida B. V. and Silva L. J.) during an initial screening procedure according to the aforementioned criteria. All eligible articles were retrieved, and whether the articles were available in full text determined the final selection. The selection process and the selected articles are shown in -Fig. $\mathbf{1}$ and in - Table 1, respectively.

\section{Data Extraction}

The data extracted from the selected studies were study design (randomized controlled trial, cohort, or case report), study sample (number of patients with schizophrenia), maximum follow-up, complications, and relevant outcome.

\section{Neurocircuitry}

Alcohol addiction is closely related to the reward system of the brain, which is part of the mesocortical and mesolimbic dopaminergic system, whose neurons are located in the ventral tegmental area (VTA) and project to the nucleus accumbens (NAcc), the septum, and the amygdala., ${ }^{4,5}$ Beyond dopamine, glutamatergic activity mediates natural reward as well as alcohol- and drug-associated reward. Elevated dopamine release, ${ }^{4}$ elevated glutamatergic transmission, and extracellular levels of glutamate in the NAcc, the basolateral amygdala, the cortex, the hippocampus, the VTA, and the posterior VTA (pVTA) are associated with ethanol consumption. 7,8

The addiction neurocircuitry model is a theory used to explain how the neurobiological processes of alcohol addiction affect brain connections. It consists of the following three major components: binge/intoxication, withdrawal/negative affect, and preoccupation/anticipation. ${ }^{9}$

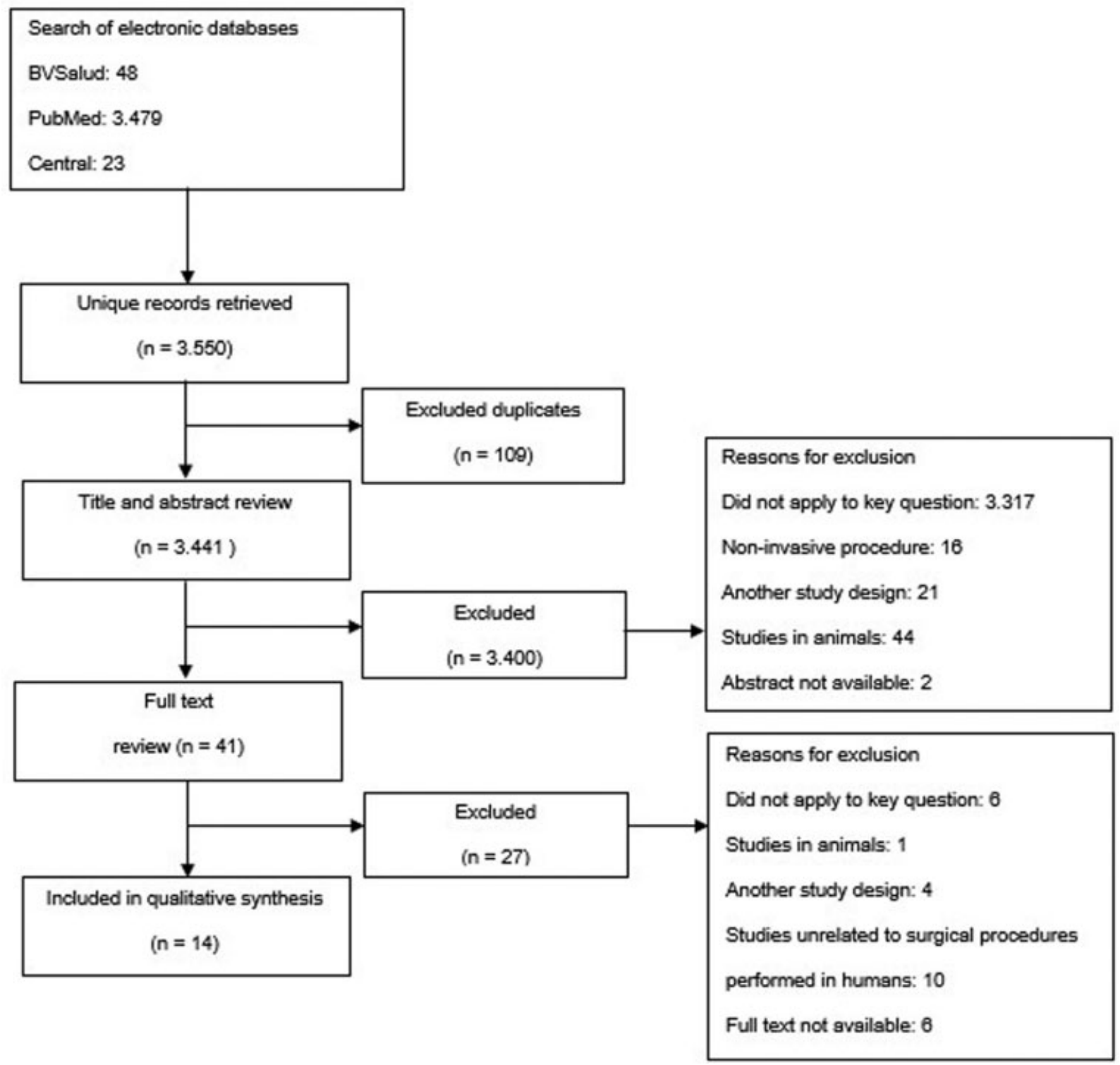

Fig. 1 Flowchart of literature review. 
Table 1 Characteristics of the studies included in the review according to the author, year, location, study design, and sample

\begin{tabular}{|l|l|l|l|l|}
\hline $\begin{array}{l}\text { Citation } \\
\text { (no.) }\end{array}$ & Author (year) & Location & Study design & Sample (no.) \\
\hline 13 & Kanaka et al., 1978 & Madras, India & Prospective cohort & $\begin{array}{l}73 \text { Patients (25 with alcohol } \\
\text { addiction) }\end{array}$ \\
\hline 15 & Müller et al., 1973 & Göttingen, Germany & Prospective cohort & $\begin{array}{l}22 \text { Patients (1 with alcohol } \\
\text { addiction) }\end{array}$ \\
\hline 16 & Dieckmann et al., 1978 & Homburg, Germany & Prospective cohort & $\begin{array}{l}13 \text { Patients with alcohol } \\
\text { addiction }\end{array}$ \\
\hline 14 & Lenhard et al., 2005 & Mannheim, Germany & Case report & 1 Patient with alcohol addiction \\
\hline $4,5,20$ & Kuhn et al., 2007 & Cologne, Germany & Case report & 1 Patient with alcohol addiction \\
\hline 17 & et al., 2013; and Müller & Magdeburg, Germany & Case series & 5 Patients with alcohol addiction \\
\hline 19 & Wu et al., 2010 & Xi'an, China & Prospective cohort & $\begin{array}{l}12 \text { Patients with alcohol } \\
\text { addiction }\end{array}$ \\
\hline 21 & Kuhn et al., 2011 & Cologne, Germany & Case report & 1 Patient with alcohol addiction \\
\hline 12 & Heldmann et al., 2012 & Magdeburg, Germany & Case report & 1 Patient with alcohol addiction \\
\hline 11 & Göktepe et al., 1975 & London, England & Retrospective cohort & $\begin{array}{l}208 \text { Patients (2 patients with } \\
\text { alcohol addiction) }\end{array}$ \\
\hline
\end{tabular}

The binge/intoxication portion of the cycle is characterized by the rewarding effects and drug-seeking behavior of any drug addiction. ${ }^{9}$ Positron emission tomography (PET) studies have shown that intoxicating doses of alcohol and drugs release dopamine and opioid peptides in the ventral striatum. Beyond that, $\gamma$-aminobutyric acid (GABA), glutamate, serotonin, acetylcholine, and endocannabinoid systems, which act at the level of either the VTA or of the NAcc, are related to this stage. ${ }^{10}$

The neurobiological mechanisms of the withdrawal/negative affect stage involve decreases in dopaminergic, serotonergic, and GABAergic transmission and increases in N-methyl-Daspartate receptors glutamatergic transmission in the NAcc. Also, the hypothalamic-pituitary-adrenal axis and the brain stress system are dysregulated by chronic alcohol use, leading to elevated adrenocorticotropic hormone, corticosterone, and amygdala corticotropin-releasing factor (CRF) during acute withdrawal. As tolerance and withdrawal evolve, elements of brain stress systems are recruited in the extended amygdala and contribute to the development of negative emotional states that lead to further drinking. ${ }^{10}$ The amygdala is connected to the NAcc through the bed nucleus of the stria terminalis. It is also connected to the orbitofrontal cortex, which may be the mechanism by which withdrawal/negative affects influence the preoccupation/anticipation stage. $^{9}$

That said, the preoccupation/anticipation stage, characterized by craving and executive function deficits, involves prefrontal activation mediated by glutamate. ${ }^{9,10}$ Beyond that, human imaging studies have reported that deficits in executive function could be associated with decreases in frontal cortex activity, which interfere with decision-mak- ing, self-regulation, inhibitory control, and working memory, and might involve disrupted GABAergic activity in the prefrontal cortex. ${ }^{10}$

In addition, the NAcc and especially the habenula, which is also involved in the reward system, project to the dorsal anterior cingulate cortex (dACC), contributing to the association between rewards and actions. The activity in the dACC increases when the received reward does not reach the desired level, also influencing actions related to craving. ${ }^{11}$

\section{Results}

From the 3,550 studies retrieved in the present research, 14 were included in the review and are synthetized in - Table 2.

Göktepe et al. evaluated the effects of stereotactic subcaudate tratotomy in 208 patients with some psychiatric disorder. Of these, only 134 had their information fully evaluated, 2 of them with alcoholism. The results were poor since the two patients remained unchanged after surgery. ${ }^{12}$

In a study by Kanaka et al., 73 drug-addicted patients, 25 of whom were alcohol dependent, underwent a stereotactic cingulotomy from 1970 to 1976 . For the authors, it was considered a failure if the patient drank alcohol after surgery. Following this criterion, among the 25 patients, 17 had a successful result and 1 died a week after surgery due to unrelated causes. ${ }^{13}$

Lenhard et al. discussed the use of anterior stereotactic cingulotomy in a case report of a 67-year-old woman. She had a history of severe alcohol intake since the age of 30 years old, characterized by high daily consumption of alcohol 


\begin{tabular}{|c|c|c|c|c|c|c|c|c|c|}
\hline 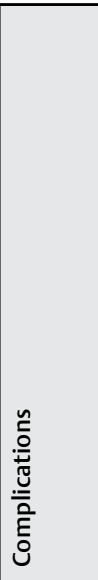 & 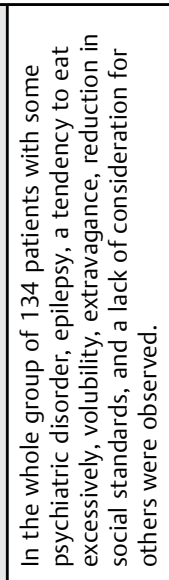 & 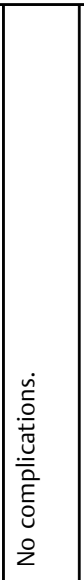 & 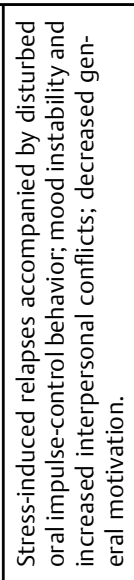 & $\mid$ & 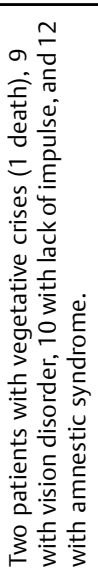 & 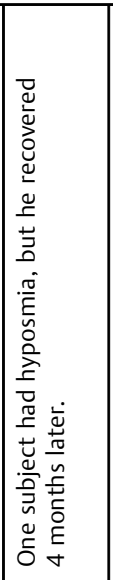 & 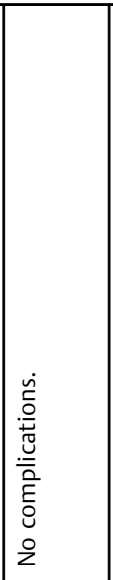 & 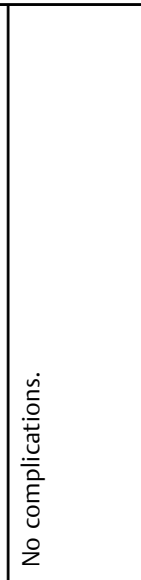 & 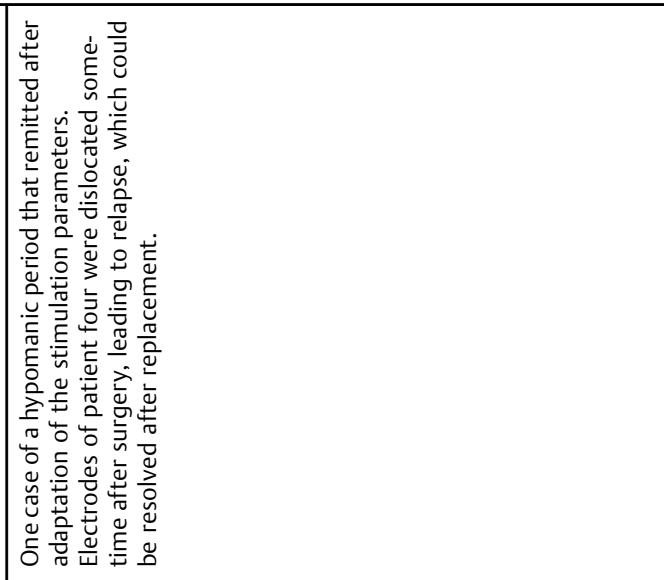 \\
\hline 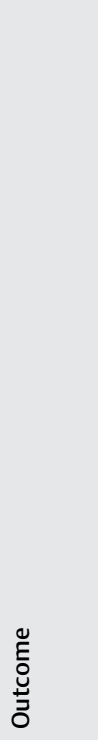 & 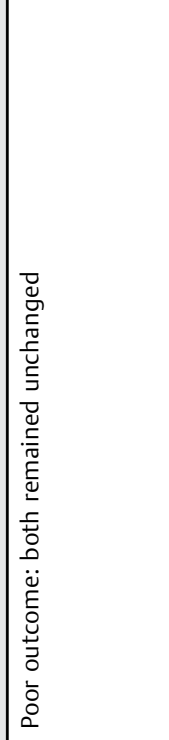 & 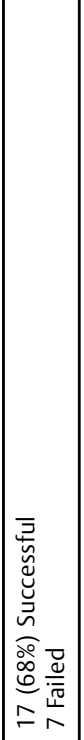 & 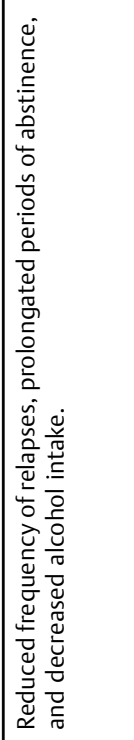 & 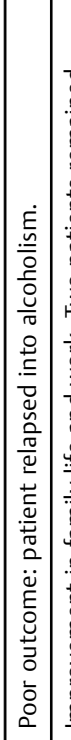 & 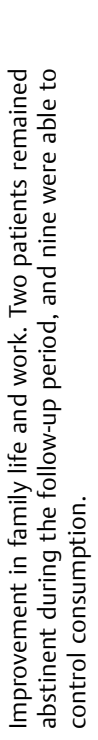 & 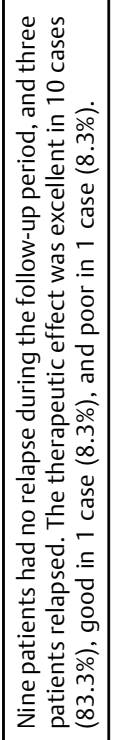 & 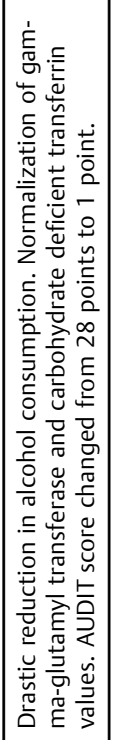 & 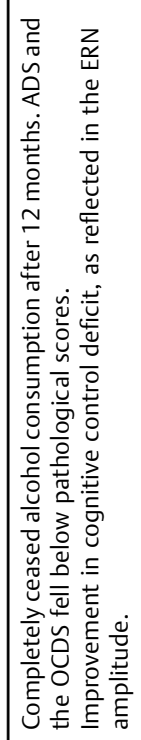 & 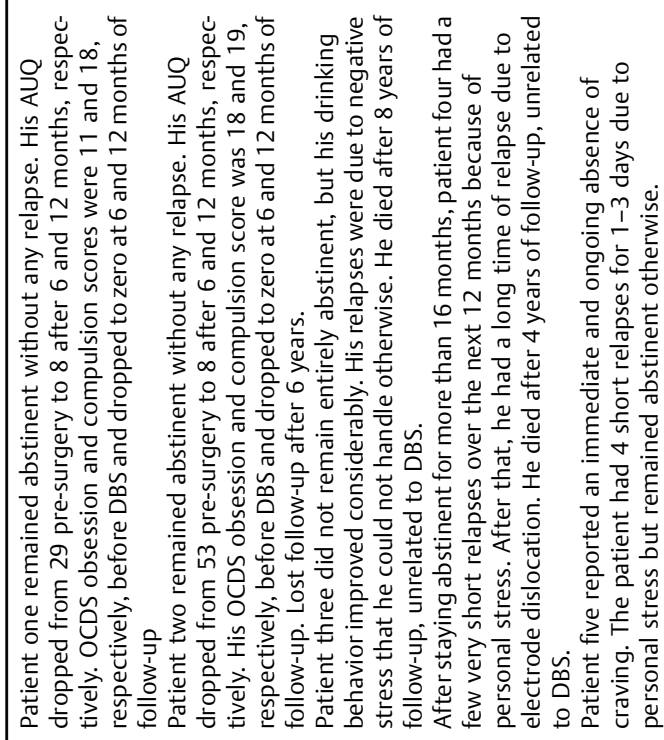 \\
\hline 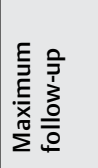 & 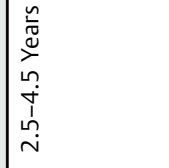 & 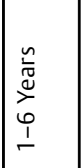 & \begin{tabular}{|l}
$\stackrel{n}{\tilde{N}}$ \\
$\stackrel{\sim}{\sim}$ \\
$\tilde{N}$
\end{tabular} & 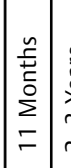 & 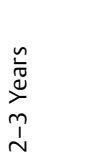 & 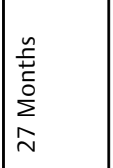 & 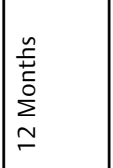 & 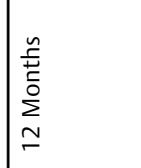 & 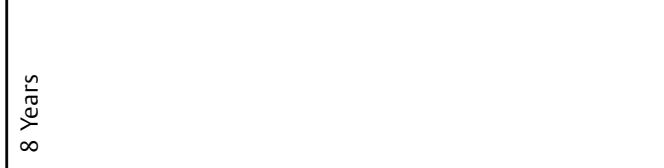 \\
\hline 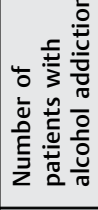 & $\sim$ & $\stackrel{\stackrel{\sim}{N}}{ }$ & - & -7 & $\stackrel{m}{=}$ & $\simeq$ & - & - & in \\
\hline 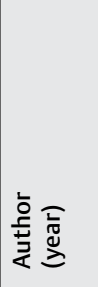 & 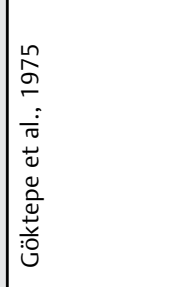 & 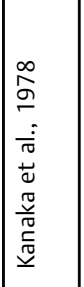 & 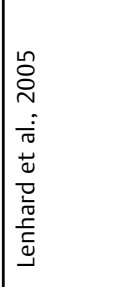 & 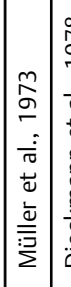 & 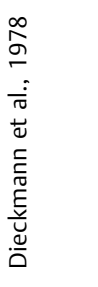 & 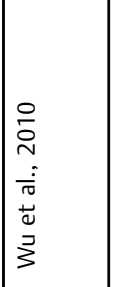 & 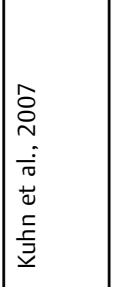 & 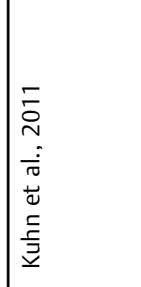 & 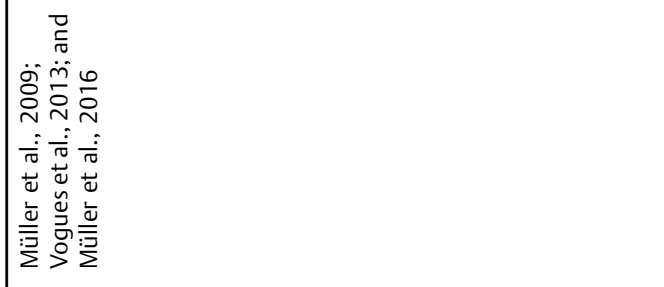 \\
\hline 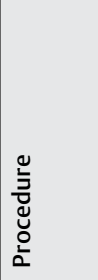 & 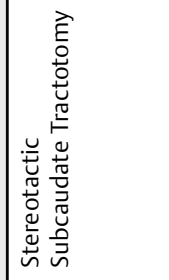 & 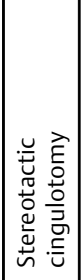 & 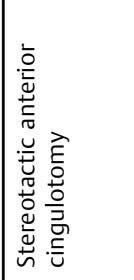 & 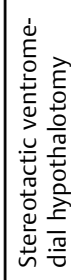 & & 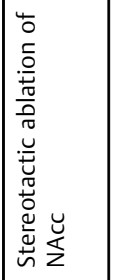 & 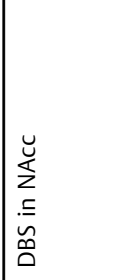 & & \\
\hline
\end{tabular}




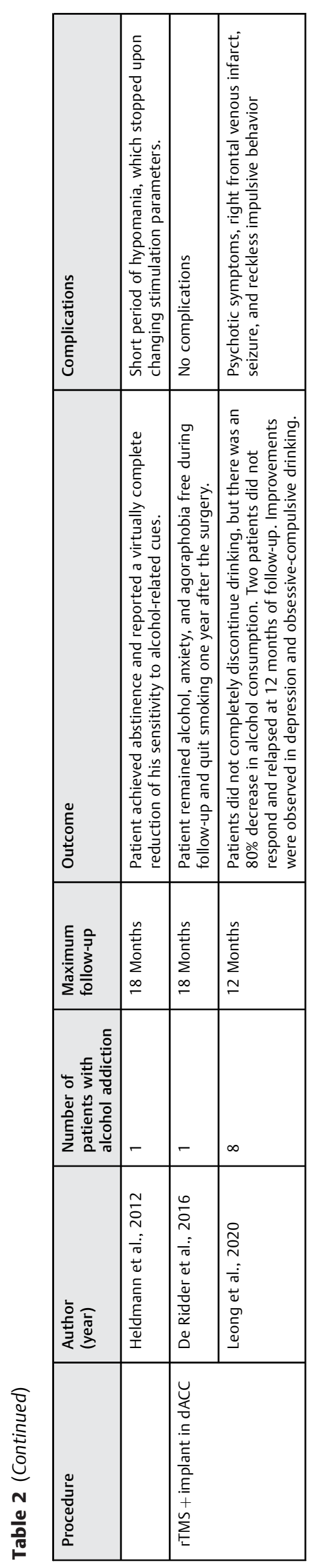

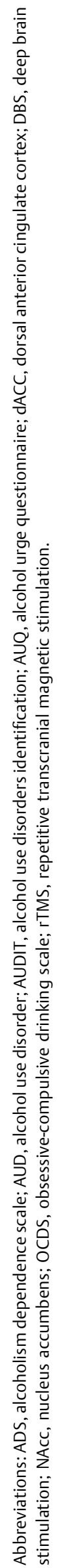

( $500 \mathrm{~g}$ of ethanol). Lesions were made in the left part of the anterior cingulate cortex, in the left caudate body, and in the dorsal medial thalamic nucleus. In the long term, the patient had fewer episodes of relapses related to stress; however, these relapses started to be accompanied by a disturbed oral impulse, such as the ingestion of perfumes, hairsprays, and other alcoholic liquids. She also had mood instability with increased interpersonal conflicts. Despite this, there was a decrease in alcohol intake and prolonged periods of abstinence. ${ }^{14}$

A different result was observed by Müller et al. using a stereotactic technique to approach the ventromedial hypothalamus. In this study, 22 male patients were operated on from 1962 to 1972 . One patient suffered with severe alcoholism for 10 years and drug addiction in the year before surgery. Previous treatment in psychiatric hospitals had not been successful. The patient was followed up for 11 months, and the result was considered bad since he continued with alcoholism. $^{15}$

Using the same target, Dieckmann et al. evaluated 13 patients with alcohol and drug addiction. As a result, there was an improvement in family life and work. Two patients remained abstinent during the follow-up period, and nine were able to control consumption. However, the side effects were notable, especially in those submitted to bilateral anterior hypothalotomy. Among them, two patients died due to a vegetative crisis, and other side effects were visual disorders, severe lack of energy, and amnestic syndrome. ${ }^{16}$

Using the stereotaxic technique for NAcc ablation, $\mathrm{Wu}$ et al. treated 12 patients with alcohol dependence. During the follow-up, 9 cases had no recurrence and had not consumed alcohol for $>6$ months, with 7 of these remaining without alcohol for $>1$ year. Relapse occurred in three cases after surgery. The result was considered excellent in 10 cases (83.3\%), good in 1 case (8.3\%), and poor in 1 case (8.3\%). The Alcohol Dependence Severity Scale (SADS) reflected a large reduction in withdrawal symptoms in the postoperative period compared with the preoperative period $(p<0.05)$. The 2 parameters that assessed the desire for alcohol (frequency and duration) were significantly reduced 6 months after surgery in these patients $(p<0.05) .{ }^{17}$

Kuhn et al. used DBS in the NAcc to primarily reduce anxiety symptoms in a 54-year-old patient who had suffered from agoraphobia with panic attacks, depressive disorder, and alcohol abuse. There was no improvement in his primary disorder, but a rapid and drastic reduction in his alcohol consumption was observed. Within 1 month of treatment, the amount of alcohol consumed decreased from 10 to 1 or 2 drinks per day, and the Alcohol Use Disorders Identification Test (AUDIT) score changed from 28 points to 1 point. Twelve months after implantation of the electrodes, the patient only consumed alcohol occasionally. ${ }^{18}$

Later, Kuhn et al. had the same positive result using DBS in the NAcc of a 69-year-old man who had been suffering from alcohol dependence for $>30$ years. Eight months after the start of DBS, the patient occasionally consumed alcohol, and after 1 year he stopped drinking completely. The authors also found a normalization of the value of the error-related 
negativity (ERN), which assesses the integrity of the anterior midcingulate cortex and the network that controls executive function. $^{19}$

Müller et al. and Vogues et al. had similar results using DBS in the NAcc to treat chronic alcoholism in five patients. Patient 1, a 36-year-old man, started drinking at 12 years old, with $\sim 2 \mathrm{~L}$ of alcoholic drinks per day. Pharmacological treatment was performed with acamprosate without success. After the start of DBS, he remained sober during the 8year follow-up period. There was no more desire for alcohol, activities of daily living could be performed normally, and there were no side effects. ${ }^{4,5,20}$

Patient 2, a 37-year-old man, started drinking at the age of 11 years old. He was also treated with acamprosate, but without effect. After the start of DBS, he remained abstinent during a 6-year follow-up period, with complete cessation of cravings. Shortly after surgery, he developed a hypomanic period for $\sim 1$ week, which was resolved after adapting the stimulation parameters. In addition to the effects on alcohol, his nicotine consumption decreased considerably. 4,5,20

Patient 3, a 40-year-old man, started drinking in his early teens and increased his daily intake over the years. Although he did not remain totally abstinent after surgery, the number of relapses and the amount of alcohol ingested decreased. His relapses were due to negative stress that he could not handle otherwise. He died after 8 years of follow-up, unrelated to DBS. ${ }^{4,5,20}$

Patient 4, who was 51 years old, had been addicted to alcohol for almost 20 years. After starting DBS therapy, this patient reported an immediate disappearance of cravings. After staying abstinent for $>16$ months, he had some very short relapses in the next 12 months due to personal stress. After $\sim 2.5$ years, the patient was lost to follow-up and had a prolonged relapse. Later, during a hospitalization due to a generalized seizure, displacement of the brain electrodes was discovered. After replacement, the patient reported a beneficial effect similar to what he had experienced shortly after surgery. He had a few more relapses after that. He died after 4 years of follow-up, unrelated to DBS.,20

Patient 5, who was 55 years old, was addicted to alcohol for $\sim 20$ years. After DBS, this patient also reported an immediate disappearance of cravings. Since the start of DBS, the patient had some relapses due to personal stress. ${ }^{5,20}$

Heldmann et al. investigated the effects of DBS on the NAcc using PET in a 38-year-old man with severe alcohol dependence. The PET showed activations related to gains and losses in the paracingulate cortex, the temporal poles, the precuneus, and the hippocampus under active DBS, which are brain areas that have been implicated in behavioral control. Except for the temporal pole, these activations were not seen when DBS was deactivated. ${ }^{21}$

De Ridder et al. used a different neuromodulation technique in a 38-year-old male patient with intractable alcohol dependence associated with anxiety and agoraphobia. First, double-cone coil transcranial magnetic stimulation was performed to verify whether an implant could be beneficial in that case, aiming to reach the dACC. As he had a great but transitory result, in order to achieve permanent benefits, an electrode was implanted onto the dACC/supplementary motor area (SMA) bilaterally. To do this, an open neurosurgical approach was performed consisting of a small right-sided frontal craniotomy for a transfalcine approach to insert two electrodes. In the 18 months of follow-up, the patient remained alcohol, anxiety, and agoraphobia free. Beyond that, he quit smoking 1 year after the surgery. ${ }^{22}$

Later, based on the methodology by De Ridder et al., Leong et al. performed surgical electrode implantation in the rostrodorsal anterior cingulate cortex ( $\mathrm{rdACC}$ ) in eight individuals with severe AUD. There was a $60.7 \%$ reduction in the alcohol craving score. The participants did not completely discontinue drinking, but there was an $80 \%$ decrease in alcohol consumption. Two patients did not respond and relapsed at 12 months of follow-up. Beyond that, improvements were observed in terms of depression and obsessive-compulsive drinking. The same was not observed for anxiety. The following side effects were observed: 2 cases of infection after internal pulse generator insertion; 1 case of psychotic symptoms 3 days postsurgery; 1 case of right frontal venous infarct 1 day postsurgery, whose hemiparesis completely resolved after 3 weeks, but there were 2 seizure episodes 26 weeks postsurgery; and 1 case of exhibited reckless impulsive behavior for 3 weeks upon returning home postsurgery. ${ }^{11}$

\section{Discussion}

When analyzing the results, we observed three approaches that had the best outcomes, which were stereotactic cingulotomy, use of the NAcc as a target, and the association of repetitive transcranial magnetic stimulation (rTMS) and an implant in the dACC.

The first study we found related to surgical treatment for alcoholism was conducted by Müller et al., in which the patients underwent a stereotactic hipothalotomy. The authors described poor results since the patient relapsed into alcoholism. Later, in a study by Dieckmann et al. using the same target, despite some beneficial results presented, the side effects were considerable, ${ }^{15,16}$ which makes this target unviable in the ablative technique.

In the meantime, Göktepe et al. evaluated several patients with different psychiatric disorders who underwent stereotactic subcaudate tratotomy. The use of a surgical approach in these cases was a consequence of the rise of psychosurgery, led by Egas Moniz in 1935, with a surgical procedure known as lobotomy. The advances in imaging techniques and the rise of stereotactic surgery made achieving better results with fewer side effects possible. ${ }^{12,23}$ Despite the poor results described by Müller et al., it was possible to envision a surgical treatment for AUD.

Cingulotomy was also an important surgical approach exploited by neurosurgeons during this period. Changes in the cingulate gyrus have been found in studies using neuroimaging in patients with alcoholism. One of the main findings was significantly reduced gray matter bilaterally. These changes were also found in the insula, in the orbitofrontal cortex, in the prefrontal cortex, and in the putamen, which are all important elements of the mesocorticolimbic 
system. ${ }^{24,25}$ In addition, maladaptive interactions in this system were observed, as well as decreased axonal integrity of the anterior corpus callosum, of the minor forceps, of the anterior corona radiata, of the cingulum, of the anterior limb of the internal capsule, and of the external capsule. ${ }^{24}$ These changes were related to the greater impulsivity found in patients with alcoholism ${ }^{24,26}$ and may explain the reasonable results when using cingulotomy as an approach.

After years of evolution in the knowledge of connections related to psychiatric disorders and substance abuse, including alcohol, the NAcc has become an important surgical target, with good results. As already elucidated, it plays a central role in the mesocorticolimbic system, being intrinsically related to addiction disorders. ${ }^{4,5,7,10}$ The NAcc has also been studied as an important target in other disorders, such as obsessive-compulsive disorder (OCD), Tourette syndrome (TS), and anxiety disorder (AD), due to the importance of the mesocorticolimbic system in these contexts. ${ }^{19,27,28}$ The influence of this target on alcoholism was first observed in one of these studies in a patient with AD. ${ }^{18}$

An important finding after DBS in the NAcc was the normalization of the ERN, an electrophysiological marker that is reduced in patients with alcohol-related disorders, demonstrating a positive effect on cognition. This may be related to the suppression of cravings and, consequently, less alcohol consumption. $^{19}$

In addition to the effects on alcoholism, another important benefit observed in studies involving DBS in the NAcc was a decrease or even cessation in smoking, showing the importance of this target and the role of the mesocorticolimbic system in the abuse of various substances and in compulsory habits. Other similar findings were made by Mantione et al. when a patient who underwent DBS for OCD presented smoking cessation and weight loss. 4,5,26,29

Regarding DBS, it is postulated that it acts by interfering in the glutamatergic and dopaminergic systems in the NAcc, indirectly influencing the dopaminergic synaptic efficiency and, consequently, resulting in the normalization of neurotransmission associated with these systems. ${ }^{18}$ This type of approach is generally preferable in relation to ablation, mainly due to its reversibility. However, the costs are much higher, which makes it infeasible in many occasions. ${ }^{17,30}$

Although noninvasive procedures are not the focus of the present study, two recent studies have demonstrated the benefits of using rTMS as a prognostic test, associated with subsequent surgical implantation of an electrode in the rdACC. In the first study, only positive results related to AUD, depression, and agoraphobia were observed in the case report, with no adverse effects. In the second study, when applying the same methodology to eight patients, it was observed that the patients, although in a smaller quantity, continued to drink. The patients attributed this result to their drinking habit, which depends on interactions between the prefrontal cortex and the dorsolateral striatum. This would probably require a different target. Although important side effects were observed, these studies show promising results. Therefore, more studies are needed to prove the efficacy and security of this procedure. ${ }^{11,22,31}$
The positive results found when using the rdACC are probably linked to its role in inhibiting the response when the individual needs to make decisions. This is very important, not only in impulsivity but also for patients to achieve abstinence, since it influences the response to stimuli related to alcohol. $^{32}$

Regardless of the positive results that have been observed when using the NAcc as a target in DBS and the association between rTMS and implants in the dACC, further studies about the effect of these and other targets on the neurocircuitry of alcohol addiction are needed to support the use of this procedure as an efficient and secure treatment option. The lack of clinical trials on alcohol abuse was the most important limitation found in the present study.

Another important limitation was the subjectivity of the data analysis in some publications and the different evaluation parameters used. Many studies used only the results observed by the patients and family members themselves and the amount of drinking ingested before and after surgery. Others used some important evaluation parameters, such as the AUDIT and the Alcoholism Dependence Scale. These differences in the evaluation of patients generates biases when comparing target results. That said, it is important to establish a common parameter for the pre- and postoperative evaluation of patients with AUD for scientific studies.

\section{Conclusion}

In conclusion, exploiting the surgical approach for patients with AUD is important since only half of the patients achieve long-term abstinence with conservative treatment. The most promising surgical targets we found were the cingulate cortex and the NAcc. Deep brain stimulation is becoming an effective technique. A recent surgical approaching associating rTMS with surgical implantation of an electrode showed interesting results and should be evaluated in more studies using the dACC and different targets.

\section{Conflict of Interests}

The authors have no conflict of interests to declare.

\section{References}

1 Global status report on alcohol and health 2018. Geneva: World Health Organization; 2018

2 Azevedo CA, Mammis A. Neuromodulation therapies for alcohol addiction: a literature review. Neuromodulation 2018;21(02): 144-148. Doi: 10.1111/ner.12548

3 American Psychiatric Association. Diagnostic and Statistical Manual of Mental Disorders. 5th edition Artmed; 2013

4 Voges J, Müller U, Bogerts B, Münte T, Heinze HJ. Deep brain stimulation surgery for alcohol addiction. World Neurosurg 2013; 80(3-4):S28.e21-31

5 Müller UJ, Sturm V, Voges J, et al. Successful treatment of chronic resistant alcoholism by deep brain stimulation of nucleus accumbens: first experience with three cases. Pharmacopsychiatry 2009;42(06):288-291

6 Gault JM, Davis R, Cascella NG, et al. Approaches to neuromodulation for schizophrenia. J Neurol Neurosurg Psychiatry 2018;89 (07):777-787 
7 Bell RL, Hauser SR, McClintick J, et al. Ethanol-associated changes in glutamate reward neurocircuitry: a minireview of clinical and preclinical genetic findings. Prog Mol Biol Transl Sci 2016; 137:41-85. Doi: 10.1016/bs.pmbts.2015.10.018

8 Burnett EJ, Chandler LJ, Trantham-Davidson H. Glutamatergic plasticity and alcohol dependence-induced alterations in reward, affect and cognition. Prog Neuropsychopharmacol Biol Psychiatry 2016;65:309-320. Doi: 10.1016/j.pnpbp.2015.08.012

9 Dean SF, Fede SJ, Diazgranados N, Momenan R. Addiction neurocircuitry and negative affect: A role for neuroticism in understanding amygdala connectivity and alcohol use disorder. Neurosci Lett 2020;722:134773

10 Koob GF, Volkow ND. Neurobiology of addiction: a neurocircuitry analysis. Lancet Psychiatry 2016;3(08):760-773. Doi: 10.1016/ S2215-0366(16)00104-8

11 Leong SL, Glue P, Manning P, et al. Anterior cingulate cortex implants for alcohol addiction: a feasibility study. Neurotherapeutics 2020;17(03):1287-1299. Doi: 10.1007/s13311-02000851-4

12 Göktepe EO, Young LB, Bridges PK. A further review of the results of sterotactic subcaudate tractotomy. Br J Psychiatry 1975; 126:270-280. Doi: 10.1192/bjp.126.3.270

13 Kanaka TS, Balasubramaniam V. Stereotactic cingulumotomy for drug addiction. Appl Neurophysiol 1978;41(1-4):86-92. Doi: $10.1159 / 000102404$

14 Lenhard T, Brassen S, Tost H, Braus DF. Long-term behavioural changes after unilateral stereotactic cingulotomy in a case of therapy-resistant alcohol dependence. World J Biol Psychiatry 2005;6(04):264-266. Doi: 10.1080/15622970510029984

15 Müller D, Roeder F, Orthner H. Further results of stereotaxis in the human hypothalamus in sexual deviations. First use of this operation in addiction to drugs. Neurochirurgia (Stuttg) 1973; 16(04):113-126. Doi: 10.1055/s-0028-1090504

16 Dieckmann G, Schneider H. Influence of stereotactic hypothalamotomy on alcohol and drug addiction. Appl Neurophysiol 1978;41(1-4):93-98. Doi: 10.1159/000102405

$17 \mathrm{Wu}$ HM, Wang XL, Chang CW, et al. Preliminary findings in ablating the nucleus accumbens using stereotactic surgery for alleviating psychological dependence on alcohol. Neurosci Lett 2010;473(02):77-81

18 Kuhn J, Lenartz D, Huff W, et al. Remission of alcohol dependency following deep brain stimulation of the nucleus accumbens: valuable therapeutic implications? J Neurol Neurosurg Psychiatry 2007;78(10):1152-1153. Doi: 10.1136/jnnp.2006.113092

19 Kuhn J, Gründler TOJ, Bauer R, et al. Successful deep brain stimulation of the nucleus accumbens in severe alcohol dependence is associated with changed performance monitoring. Addict Biol 2011;16(04):620-623
20 Müller UJ, Sturm V, Voges J, et al. Nucleus accumbens deep brain stimulation for alcohol addiction-safety and clinical long-term results of a pilot trial. Pharmacopsychiatry 2016;49(04):170-173. Doi: $10.1055 / \mathrm{s}-0042-104507$

21 Heldmann M, Berding G, Voges J, et al. Deep brain stimulation of nucleus accumbens region in alcoholism affects reward processing. PLoS One 2012;7(05):e36572. Doi: 10.1371/journal.pone.0036572

22 De Ridder D, Manning P, Glue P, Cape G, Langguth B, Vanneste S. Anterior cingulate implant for alcohol dependence: case report. Neurosurgery 2016;78(06):E883-E893. Doi: 10.1227/NEU.0000000000001248

23 Almeida BV, Aquino IP, Silva LJ. Neurosurgery for Refractory Schizophrenia: A Systematic Literature Review. Arq Bras Neurocir Brazilian Neurosurg 2020;39(02):108-115

24 Wang J, Fan Y, Dong Y, et al. Alterations in brain structure and functional connectivity in alcohol dependent patients and possible association with impulsivity. PLoS One 2016;11(08): e0161956. Doi: 10.1371/journal.pone.0161956

25 Demirakca T, Ende G, Kämmerer N, et al. Effects of alcoholism and continued abstinence on brain volumes in both genders. Alcohol Clin Exp Res 2011;35(09):1678-1685. Doi: 10.1111/j.15300277.2011.01514.X

26 Kuhn J, Bauer R, Pohl S, et al. Observations on unaided smoking cessation after deep brain stimulation of the nucleus accumbens. Eur Addict Res 2009;15(04):196-201

27 Sturm V, Lenartz D, Koulousakis A, et al. The nucleus accumbens: a target for deep brain stimulation in obsessive-compulsive- and anxiety-disorders. J Chem Neuroanat 2003;26(04):293-299

28 Kuhn J, Lenartz D, Mai JK, et al. Deep brain stimulation of the nucleus accumbens and the internal capsule in therapeutically refractory Tourette-syndrome. J Neurol 2007;254(07):963-965

29 Mantione M, van de Brink W, Schuurman PR, Denys D. Smoking cessation and weight loss after chronic deep brain stimulation of the nucleus accumbens: therapeutic and research implications: case report. Neurosurgery 2010;66(01):E218-, discussion E218. Doi: 10.1227/01.NEU.0000360570.40339.64

30 Mikell CB, McKhann GM, Segal S, McGovern RA, Wallenstein MB, Moore $\mathrm{H}$. The hippocampus and nucleus accumbens as potential therapeutic targets for neurosurgical intervention in schizophrenia. Stereotact Funct Neurosurg 2009;87(04):256-265

31 Everitt BJ, Robbins TW. Neural systems of reinforcement for drug addiction: from actions to habits to compulsion. [published correction appears in Nat Neurosci 2006 Jul;9(7):979]Nat Neurosci 2005;8(11):1481-1489. Doi: 10.1038/nn1579

32 Bauer J, Pedersen A, Scherbaum N, et al. Craving in alcoholdependent patients after detoxification is related to glutamatergic dysfunction in the nucleus accumbens and the anterior cingulate cortex. Neuropsychopharmacology 2013;38(08): 1401-1408. Doi: 10.1038/npp.2013.45 